•保护论坛・

\title{
探讨我国与邻国共有药用植物的惠益分享机制
}

\author{
刘文静 徐 靖* 银森录 田 瑜 李俊生 \\ (中国环境科学研究院生物多样性研究中心, 北京 100012)
}

\begin{abstract}
摘要: 多国共有遗传资源的惠益分享是全球多边惠益分享机制谈判中的重要议题。我国邻国众多, 掌握我国与邻 国共有药用植物的数量和空间分布格局是我国参加全球多边惠益分享机制谈判应当关注的焦点问题。本文对我国 与邻国共有药用植物的地理分布格局进行了分析。结果表明, 我国药用植物多与东南亚、东北亚及南亚的国家(地 区)所共有, 其中与越南共有的药用植物数量最多(220种), 其次为日本(144种), 再次为缅甸(75种), 第4为印度 (42 种), 我国与邻国共有药用植物呈现地区集中性。由此得出的结论有：(1)与亚洲国家(地区)探讨建立次区域性质的 多边惠益分享机制对于我国具有重要意义和价值; (2)应重视与东南亚、南亚和东北亚等共有药用植物较多国家(地 区)的双边合作; (3)由于 《名古屋议定书》跨界合作条款短时间内难以发挥作用，目前应支持多边惠益分享机制的 讨论, 为我国完善国内立法和推动次区域谈判争取时间。
\end{abstract}

关键词：遗传资源; 名古屋议定书; 获取与惠益分享; 全球多边惠益分享机制; 跨界合作

\section{Mechanisms of benefit-sharing of medicinal plants found in China and neighboring countries}

\author{
Wenjing Liu, Jing Xu*, Senlu Yin, Yu Tian, Junsheng Li \\ Biodiversity Research Center, Chinese Academy of Environmental Sciences, Beijing 100012
}

\begin{abstract}
The genetic resources that are commonly shared by many countries are a core issue in the negotiation of the Global Multilateral Benefit-Sharing Mechanism (GMBSM). Because China is a country that has many neighboring countries, understanding the partitioning and spatial patterns is a key issue in China's participation in the GMBSM negotiation. We analyze the geographical distribution of the plants which are shared among China and its neighboring countries and regions. The results indicate that medicinal plants found in China are commonly shared with Southeast Asia, Northeast Asia, and South Asia. Among them, China shares the most medicinal plants (220 species) with Vietnam, followed by Japan (144 species) and Myanmar (75 species), and lastly India (42 species). This study shows that: (1) Discussing the establishment of a regional multilateral benefit-sharing mechanism is significant to China; (2) China should pay more attention to bilateral cooperation with neighboring countries and regions found in Southeast Asia, Northeast Asia, and South Asia, as these regions share the most medicinal plants, and (3) Due to the transboundary situation clause in the Protocol is hard to play its role in a short time, additional support is needed in the negotiation of GMBSM in order to allow more time for China's domestic legislation and sub-regional negotiation.
\end{abstract}

Key words: genetic resources; Nagoya Protocol; access and benefit-sharing; global multilateral benefitsharing mechanism; transboundary cooperation

《名古屋议定书》通过后, 全球多边惠益分享 机制(Global Multilateral Benefit-Sharing Mechanism, GMBSM)成为遗传资源获取与惠益分享谈判进程 中的重要议题。《名古屋议定书》第10条要求缔约
方考虑GMBSM的必要性及其模式，目的是处理在 跨界以及无法准予或获得事先知情同意的情况下 公平公正地分享因利用遗传资源及其相关的传统 知识产生的惠益(SCBD, 2011)。GMBSM巧妙地规 
避了议定书的时间和地理范围这个长期争执无果 的问题(Chee, 2010; 薛达元, 2010), 是未经谈判但 被谈判各方接受的折中条款(张小勇, 2017)。非洲集 团认为, 必须建立GMBSM, 以解决多国共有遗传 资源的获取与惠益分享问题; 欧盟等则认为, 应当 广泛收集各方观点和建议, 以确定GMBSM是否适 用于多国共有遗传资源的情况(徐靖等, 2013)。

2016年12月召开的《名古屋议定书》缔约方大 会第二次会议邀请各方提供执行议定书时遇到的 无法用双边模式处理的情况(SCBD, 2016a), 这充 分说明目前包括中国在内的各国均缺乏数据来支 撑其观点, GMBSM 条款可能推迟甚至可能继续规 避议定书的时间和地理范围等具有根本性争议的 问题(Greiber et al, 2012)。可以预见, 各方就 GMBSM达成一致前, 将会进行长时间反复的协商 (Nijar, 2011)。因此, 掌握本国与其他大洲、次区域 及国家(地区)共有遗传资源的基本情况, 是各方确定 谈判立场并判定建立GMBSM必要性的关键指标。

医药用途的遗传资源获取与惠益分享是遗传 资源获取与惠益分享国际制度的重点关注领域。我 国药用植物丰富, 且利用历史悠久。第三次中药资 源普查结果显示, 我国现有记载的药用植物达 11,146种(张惠源等, 1995), 已知临床常用的植物药 材达700多种(董静洲等, 2005)。此外, 我国民族众多, 各族人民在数千年的生产和生活实践中创造了丰 富的传统知识, 包括中医药和民族医药在内的传统 医药闻名世界(薛达元等, 2012)。同时, 我国也一直 是国外机构和个人获取遗传资源的重要目标国(毕列 爵, 1983; 武建勇等, 2011a, b, 2013)。因此, 我国与 他国(地区)共有药用资源的惠益分享制度与我国的 利益密切相关, 亟需了解与他国(地区)共有药用植 物的现状, 确立我国在国际谈判中的立场。

生物遗传资源的分布往往是依据自然边界, 而 非国家边界。虽然已有学者对我国植物的分布区类 型进行过系统的研究 (吴征镒, 1991; 吴征镒等, 2003), 但未明确植物遗传资源的所属国家, 而《名 古屋议定书》承认国家对管辖范围内的生物遗传资 源拥有主权, 获取与惠益分享活动须明确遗传资源 的所属国家。为此, 本文以我国与他国(地区)共有的 药用植物为研究对象, 以国家(地区)边界统计药用 植物的分布格局, 分析我国与他国(地区)共有的药用 植物的数量, 以掌握与他国(地区)共有药用植物的空
间分布情况, 为我国参与GMBSM议题谈判及次区域 合作提供参考。

\section{1 数据与方法}

\section{1 数据来源}

本文首先由中国科学院植物研究所覃海宁教 授基于《中国生物物种名录(2013年版)》的高等植 物名录(Qin et al, 2013) 提取在国外也有分布记录 的种子植物种类。在此基础上, 作者与 Huang 等 (2011)发表的我国特有种子植物名录进行比对, 排 除其中的重复物种。然后由中国中医科学院中药研 究所杨光博士与全国中药资源普查数据库中的药 用植物名录进行比对, 获得我国与他国(地区)共有 的药用种子植物 4,265 种。最后作者通过检索《中国 植物志》(中国科学院《中国植物志》编辑委员会, 2004)和Flora of China (Wu et al, 2013), 确定4,265 种共有药用种子植物的洲际分布和国家(地区)分布 信息。据此, 本文建立了包括物种名(拉丁名和中文 名)、属名(拉丁名和中文名)、科名(拉丁名和中文 名)、国外地理分布范围在内的与他国(地区)共有的 药用种子植物信息库。本文所述 “共有” 药用种子植 物, 是指依据《中国植物志》和Flora of China的记 载, 同时分布于我国和其他国家(地区)的药用植物, 包括原产于我国和其他国家(地区)的物种以及引种 栽培和外来归化的物种。

\section{2 研究方法}

统计我国与他国(地区)共有的药用植物的分类 情况，基于全球、次区域和国家(地区)三个尺度分析 其地理分布情况。本研究中, 全球尺度分为亚洲、 欧洲、大洋洲、非洲和美洲 5 大洲。亚洲次区域尺 度分为东北亚、东南亚、南亚、中亚和西亚 5 个次 区域。对 5 个次区域进一步划分如下: 东北亚分为蒙 古、朝鲜半岛和日本; 东南亚分为菲律宾、越南、 老挝、柬埔寨、缅甸、泰国、马来西亚、文莱、新 加坡、印度尼西亚和东帝汶; 南亚分为尼泊尔、不 丹、孟加拉国、印度、巴基斯坦、斯里兰卡、马尔 代夫、克什米尔、阿富汗和伊朗; 中亚分为哈萨克 斯坦、吉尔吉斯斯坦、塔吉克斯坦、乌兹别克斯坦 和土库曼斯坦; 西亚分为巴林、科威特、阿曼、卡 塔尔、沙特阿拉伯、阿联酋、伊拉克、约旦、黎巴 嫩、巴勒斯坦和叙利亚。此外, 俄罗斯虽属于欧洲, 但与我国接壤, 因此也加入国家(地区)尺度的分析。 


\section{2 研究结果}

\section{1 共有药用植物统计}

我国与他国(地区)共有种子植物15,140种(隶属 于253科 2,893属)。其中, 有药用价值的植物物种数 量共计4,265种, 隶属于 216 科 1,581 属, 占共有种子 植物物种总数的 $28.17 \%$, 其中有 121 种(46科104属) 原产于其他国家(地区)。

我国与他国(地区)共有的药用植物中, 蓼科蓼 属(Polygonum)有44种; 菊科蒿属(Artemisia)有34种; 大戟科大戟属 (Euphorbia) 有 31种; 兰科石斛属 (Dendrobium) 有30种。

此外, 药用植物物种数量在 20-30种之间的科 属分别为罂罊科紫堇属(Corydalis)、蓄薇科的委陵 菜属(Potentilla)及悬钩子属(Rubus)、毛茛科铁线莲 属(Clematis)及乌头属(Aconitum)、桑科榕属(Ficus)、 薯蓣科薯蓣属(Dioscorea)、杜鹃花科杜鹃花属 (Rhododendron)和鸢尾科凮尾属(Iris)。其余科属药 用植物物种数量均在 20 种以下。

\section{2 共有药用植物在全球尺度的分布格局}

我国与全球其他国家(地区)共有药用植物 4,265 种。其中, 有 2,509 种(隶属于 172 科 1,040 属) 与亚洲国家(地区)共有, 占 $58.83 \%$ 。在两大洲及以
上范围内分布的共有药用植物为 1,534 种(隶属于 152 科 794 属), 占 $35.97 \%$ 。此外, 世界范围内广泛 分布的药用植物仅 222 种(隶属 59 科 176 属), 仅占 $5.21 \%$ 。

\section{3 共有药用植物在亚洲次区域尺度的分布格局}

我国与亚洲其他国家(地区)共有药用植物物种 数量为2,509种。其中, 与单独一个次区域共有的药 用植物共1,360种(隶属于153科678属), 占在亚洲分 布的共有药用植物的 $54.20 \%$ 。结果显示，我国与东 南亚、东北亚、南亚共有药用植物种数最多(表2)。 与两个及以上次区域共有药用植物 1,137 种(隶属于 151科646属), 占在亚洲分布的共有药用植物的 $45.32 \%$ 。在亚洲范围内广泛分布的药用植物仅有 12 种(隶属于 7 科 12 属), 所占比例仅为 $0.48 \%$ 。

\section{4 共有药用植物在国家(地区)尺度的分布格局}

研究结果显示, 我国和周边邻近国家(地区)单 独共有药用植物数量为 680 种，隶属于 121 科 416 属 (表3), 主要是与我国陆地接壤或隔海相望的国家 (地区)。

按照与单个国家(地区)共有药用植物数量进行 排序，我国与越南共有的药用植物数量最多，其次 为日本, 再次为与缅甸和印度。

\section{表1 我国与他国(地区)共有药用植物在全球尺度的分布格局}

Table 1 Distribution of medicinal plants commonly shared with other countries at global scale

\begin{tabular}{llll}
\hline 大洲 Continents & 种 Species (\%) & 属 Genus & 科 Family \\
\hline 总计 Total & $4,265(100)$ & 1,581 & 216 \\
亚洲 Asia & $2,509(58.83)$ & 1,040 & 172 \\
欧洲、亚洲 Europe and Asia & $856(20.07)$ & 419 & 95 \\
世界广布 Widely distributed in the world & $222(5.21)$ & 176 & 59 \\
亚洲、大洋洲 Asia and Oceania & $171(4.01)$ & 142 & 66 \\
欧洲、亚洲、美洲 Europe, Asia and America & $127(2.98)$ & 101 & 13 \\
亚洲、美洲 Asia and America & $88(2.06)$ & 67 & 39 \\
亚洲、非洲 Asia and Africa & $75(1.76)$ & 70 & 27 \\
亚洲、大洋洲、非洲 Asia, Oceania and Africa & $62(1.45)$ & 52 & 28 \\
欧洲、亚洲、非洲 Europe, Asia and Africa & $55(1.29)$ & 48 & 15 \\
欧洲、亚洲、大洋洲 Europe, Asia and Oceania & $20(0.47)$ & 20 & 13 \\
欧洲、亚洲、非、美洲 Europe, Asia, Africa and America & $20(0.47)$ & 18 & 13 \\
亚洲、大洋洲、非洲、美洲 Asia, Oceania, Africa and America & $19(0.45)$ & 18 & 11 \\
欧洲、亚洲、大洋洲、美洲 Europe, Asia, Oceania and America & $13(0.3)$ & 13 & 9 \\
欧洲、亚洲、大洋洲、非洲 Europe, Asia, Oceania and Africa & $12(0.28)$ & 11 & 7 \\
亚洲、大洋洲、美洲 Asia, Oceania and America & $8(0.19)$ & 8 & 7 \\
亚洲、非洲、美洲 Asia, Africa and America & $8(0.19)$ & 8 & \\
\hline
\end{tabular}


表2 与他国(地区)共有的药用植物在亚洲各次区域尺度分布格局

Table 2 Distribution of medicinal plants commonly shared with other countries at sub-regional scale

\begin{tabular}{|c|c|c|c|}
\hline 次区域 Sub-region & 种 Species $(\%)$ & 属 Genus & 科 Family \\
\hline 总计 Total & $2,509(100)$ & 1,040 & 172 \\
\hline 东南亚、南亚 Southeast Asia and South Asia & 836(33.32) & 509 & 132 \\
\hline 东南亚 Southeast Asia & $630(25.11)$ & 385 & 122 \\
\hline 东北亚 Northeast Asia & 375(14.95) & 259 & 97 \\
\hline 南亚 South Asia & 284(11.32) & 206 & 82 \\
\hline 东北亚、东南亚、南亚 Northeast Asia, Southeast Asia and South Asia & $117(4.66)$ & 100 & 51 \\
\hline 东北亚、东南亚 Northeast Asia and Southeast Asia & 91(3.63) & 80 & 50 \\
\hline 中亚 Central Asia & $63(2.51)$ & 50 & 23 \\
\hline 东北亚、南亚 Northeast Asia and South Asia & $27(1.08)$ & 27 & 19 \\
\hline 南亚、中亚 South Asia and Central Asia & $22(0.88)$ & 21 & 14 \\
\hline 东北亚、中亚 Northeast Asia and Central Asia & $17(0.68)$ & 15 & 10 \\
\hline 亚洲广布 Widely distributed in Asia & 12(0.48) & 12 & 7 \\
\hline 东北亚、南亚、中亚 Northeast Asia, South Asia and Central Asia & $10(0.4)$ & 10 & 9 \\
\hline 西亚 West Asia & $8(0.32)$ & 8 & 7 \\
\hline 南亚、西亚 South Asia and West Asia & $4(0.16)$ & 4 & 4 \\
\hline 东北亚、中亚、西亚 Northeast Asia and West Asia & $3(0.12)$ & 2 & 2 \\
\hline 东南亚、南亚、西亚 Southeast Asia, South Asia and West Asia & $3(0.12)$ & 3 & 3 \\
\hline 东北亚、南亚、中亚、西亚 Northeast Asia, South Asia, Central Asia and West Asia & $2(0.08)$ & 2 & 2 \\
\hline 东北亚、东南亚、南亚、中亚 Northeast Asia, Southeast Asia, South Asia and Central Asia & $1(0.04)$ & 1 & 1 \\
\hline 东北亚、南亚、西亚 Northeast Asia, South Asia and West Asia & $1(0.04)$ & 1 & 1 \\
\hline 东南亚、南亚、中亚 Southeast Asia, South Asia and Central Asia & $1(0.04)$ & 1 & 1 \\
\hline 南亚、中亚、西亚 South Asia, Central Asia and West Asia & $1(0.04)$ & 1 & 1 \\
\hline 中亚、西亚 Central Asia and West Asia & $1(0.04)$ & 1 & 1 \\
\hline
\end{tabular}

表3 与周边邻国共有药用植物在国家(地区)尺度分布格局

Table 3 Distribution of medicinal plants commonly shared with other countries/regions at national scale

\begin{tabular}{llll}
\hline 国家(地区) Countries/regions & 种 Species (\%) & 属 Genus & 科 Family \\
\hline 总计 Total & $680(100)$ & 416 & 121 \\
越南 Vietnam & $220(32.35)$ & 168 & 84 \\
日本 Japan & $144(21.18)$ & 116 & 60 \\
缅甸 Myanmar & $75(11.03)$ & 60 & 43 \\
印度 India & $42(6.18)$ & 41 & 27 \\
朝鲜半岛 Korean peninsula & $39(5.74)$ & 35 & 23 \\
俄罗斯 Russia & $29(4.26)$ & 28 & 13 \\
泰国 Thailand & $27(3.97)$ & 24 & 19 \\
蒙古 Mongolia & $21(3.09)$ & 19 & 13 \\
尼泊尔 Nepal & $19(2.79)$ & 18 & 17 \\
不丹 Bhutan & $16(2.35)$ & 15 & 14 \\
哈萨克斯坦 Kazakhstan & $16(2.35)$ & 14 & 8 \\
老挝 Laos & $7(1.03)$ & 7 & 7 \\
印度尼西亚 Indonesia & $6(0.88)$ & 5 & 5 \\
菲律宾 Philippines & $6(0.88)$ & 6 & 6 \\
吉尔吉斯斯坦 Kyrgyzstan & $4(0.59)$ & 4 & 4 \\
克什米尔 Kashmir & $3(0.44)$ & 3 & 2 \\
马来西亚 Malaysia & $2(0.29)$ & 2 & 2 \\
柬埔寨 Cambodia & $1(0.15)$ & 1 & 1 \\
巴基斯坦 Pakistan & $1(0.15)$ & 1 & 1 \\
孟加拉国 Bangladesh & $1(0.15)$ & 1 & 1 \\
塔吉克斯坦 Tajikistan & $1(0.15)$ & 1 & 1 \\
\hline & & &
\end{tabular}

按照国家(地区)所在地理位置进行归类，与我 国单独共有药用植物数量最多的国家(地区)主要分 布在东南亚(越南、缅甸、泰国、老挝、印度尼西亚、 菲律宾、马来西亚和柬埔寨), 共344种(隶属于97科 238属); 然后依次为东北亚(日本、朝鲜半岛和蒙 古）204种(隶属于69科158属)和南亚(印度、尼泊尔、 不丹、克什米尔、巴基斯坦和孟加拉国)82种(隶属 于44科78属)。与中亚(哈萨克斯坦、吉尔吉斯斯坦 和塔吉克斯坦)共有药用植物数量相对较少, 共21 种(隶属于12科19属)。另外，与俄罗斯共有药用植 物29种。

\section{3 讨论}

\section{1 关于研究数据}

本研究以我国现有已公开发表的植物物种名 录为基础，尝试通过对现有植物调查、分类和编目 基础研究数据的再加工，分析我国对将GMBSM适 用于跨境共有遗传资源的应有态度，识别我国在遗 传资源获取和惠益分享跨境合作问题上的重点国 家(地区), 为我国参加《名古屋议定书》谈判提供参 
考。从了解我国与他国(地区)共有药用种子植物的 总体趋势这一角度来看, 本研究所用数据可以满足 这一需求。当然, 由于GMBSM问题的谈判仍在进 行, 随着今后植物调查、分类与编目研究的深入, 植物物种名录的不断完善, 不排除采用更新的数据 对此问题进一步研究的可能性。

\section{2 “跨界合作”的可行性}

《名古屋议定书》第11条规定, 缔约方可以通 过跨界合作来处理多国共有药用植物惠益分享问 题。但该条款并未对缔约方提出强制性义务, 完全 属于自愿性质, 其实施效果将依赖于国内立法, 目 前很难真正发挥作用。截至2017年5月22日, 亚洲只 有17个国家成为《名古屋议定书》缔约方, 其中, 蒙 古、老挝、越南、缅甸、印度、不丹、巴基斯坦、 塔吉克斯坦、哈萨克斯坦和吉尔吉斯斯坦这 10 个国 家是我国的陆地接壤邻国。但只有印度、不丹和菲 律宾这3个国家制定了遗传资源获取与惠益分享国 内立法, 且其立法中尚无与跨界合作相关的规定, 依托跨界合作处理与他国(地区)共有药用植物的惠 益分享问题缺乏法律依据。因此, 以跨界合作的方 式解决我国与他国(地区)共有药用植物的获取与惠 益分享问题尚不可行, 这为建立多边惠益分享机制 提供了空间。

\section{3 多边惠益分享机制在不同尺度的可行性}

GMBSM虽为处理多国共有遗传资源的获取与 惠益分享问题提供了潜在解决方案, 但我国与他国 (地区)共有的药用植物中仅有两百余种是世界广布 种, 数量相对较少。而药用植物开发需要较长周期, 短期内难以产生足以分享的全球性货币性收益, 少 量药用植物开发产生的惠益很可能无法支撑 GMBSM运行所需成本。因此, 目前来看在全球层 面建立多边惠益分享机制缺乏可操作性。

我国与他国(地区)共有的药用植物有 $58.83 \%$ 集 中分布在亚洲, 与东南亚、南亚、东北亚等国家(地 区)共有药用植物总数比例更是高达 $84.7 \%$, 呈现出 明显的地区集中性。这表明亚洲国家(地区)之间具 备建立多边惠益分享机制的基本条件, 同时也存在 较强需求。

\section{4 栽培植物和归化种的惠益分享机制}

本研究建立的数据库中包含百余种与他国(地 区)共有的药用栽培植物。但这些药用植物的引种时 间不明确, 甚至有很多种的原产国不详, 如菊科的
金盏花 (Calendula officinalis) 和红花 (Carthamus tinctorius)、姜科的姜黄(Curcuma longa)、苋科的反 枝苋(Amaranthus retroflexus)。对此，应该区别传统 利用和依赖生物技术产生高附加值产品的创新型 利用这两种方式。如果进行引种栽培目的是非商业 性观赏或食用, 则无须分享惠益; 如果研发药品, 则需要进一步考虑其惠益分享机制。此外, 我国也 有一些与他国共有的药用植物是归化种, 对此, 应 该同样区分获取目的和用途, 再选择适用的惠益分 享机制。

\section{4 政策建议}

\section{1 在国内立法中加入跨界合作规定}

我国已加入《名古屋议定书》, 需要依据国内 立法来处理多国共有药用植物获取与惠益分享问 题。但目前国内立法体系还不完善(赵富伟和薛达元, 2008), 与邻国跨界合作缺乏法律依据, 建议在国内 立法中加入跨界合作的规定, 积极应对与邻国共有 药用植物获取与惠益分享问题。

与此同时, 我国应当在《名古屋议定书》后续 谈判中支持GMBSM谈判进程, 并表达在次区域层 面建立多边惠益分享机制的观点, 积极寻求邻国的 理解和支持。通过推动国际谈判, 为我国制定遗传 资源获取与惠益分享国内立法和次区域层面的谈 判争取时间。

\section{2 有针对性地与邻国开展合作}

针对与单个接壤国家(地区)共有的药用植物, 应采用双边合作的方式, 两国设立统一的获取和惠 益分享标准, 共同应对其他国家(地区)获取共有药 用植物，同时共同开发利用共有药用植物。其中， 重点合作对象为越南、缅甸和印度等与我国单独共 有药用植物数量较多的接壤国家。

针对与多个接壤国家(地区)共有的药用植物, 应考虑次区域层面的合作。我国应在同时符合我国 和这些国家(地区)国内立法的前提下, 积极推动与 这些接壤国家(地区)建立次区域层面的多边惠益分 享机制, 争取建立相对一致的获取与惠益分享标准, 共同应对发达国家获取共有药用植物的需求, 同时 共同开发共有药用植物。其中, 在次区域层面的重 点碰商对象是东南亚的越南、缅甸、老挝, 南亚的 印度、尼泊尔和不丹, 中亚主要是哈萨克斯坦、吉 尔吉斯斯坦和塔吉克斯坦。 
针对与单个非接壤国家(地区)共有的药用植物, 由于这些国家(地区)与我国没有共同边境，两国共 有的药用植物是否适用于 《名古屋议定书》第11条 仍存在争议。为避免使用者竞相到获取与惠益分享 要求低甚至没有要求的原产国获取药用植物, 从而 促使共有药用植物的多个原产国之间产生“逐底竞 争”, 最终导致共有药用植物的获取与分享活动完 全偏离《名古屋议定书》保护生物多样性的初衷, 因 此不能将这类资源纳入 《名古屋议定书》的“双边 模式”来处理。我国应积极与其进行双边合作, 共同 应对其他国家(地区)的获取活动。其中, 双边合作的 对象主要是日本和韩国。

针对多个非接壤国家(地区), 主要包括菲律 宾、马来西亚、文莱、印度尼西亚在内的与我国隔 海相望的东南亚国家, 我国与上述国家共有的药用 植物是否适用于 《名古屋议定书》第11条仍存在争 议, 我国应优先考虑多边合作的方式。

针对世界广布种, 原则上考虑纳入全球多边惠 益分享机制, 但是目前来看不具有可操作性。我国 应该积极跟踪和参与GMBSM议题的后续谈判, 并 重点关注关于遗传资源的数字序列信息 (SCBD, 2016b)等其他具有潜在惠益分享价值的标的物的谈 判动向。

此外, 应注意有些药用植物与其他大洲的国家 (地区)共有, 例如非洲和南美洲国家(地区)。由于这 些国家(地区)与我国距离较远, 共有药用植物一般 属于栽培植物或者广布种, 因此, 无须特别考虑与 这些国家(地区)的合作, 按照栽培植物或广布种的 方式处理即可。

\section{3 明确栽培植物和归化种的惠益分享问题}

为明确栽培植物和归化种的惠益分享机制, 应 该首先摸清其原产国家(地区), 然后明确其使用目 的, 如果进行商业开发, 再根据不同的情况选择合 适的惠益分享机制。对于原产地不明确的栽培植物 和归化种, 应该研究纳入GMBSM; 对于已知原产 国的栽培植物和归化种, 应该与原产国协商采用 《名古屋议定书》确定的“双边模式”来处理惠益分 享问题。此外, 应该注意到许多药用栽培植物已被 培育成新品种, 应该尊重《国际植物新品种保护公 约》赋予育种者的权利, 在法律规定的期限内具有 控制新品种的繁殖、使用以及销售的权利, 这类遗 传资源无须纳入多边惠益分享机制。
致谢: 特别感谢中国科学院植物研究所覃海宁教 授和中国中医科学院中药研究所杨光博士为本文 研究数据提供帮助。感谢中国科学院植物研究所刘 冰研究员和于胜祥博士以及中国环境科学研究院 关潇博士为本文涉及的科属名称核对工作提供帮 助。感谢审稿专家和责任编委为本文提出宝贵的意 见和建议。

\section{参考文献}

Bi LJ (1983) The botanical exploration in China by western countries during the 149 years (1800-1949) before liberation. Wuhan Botanical Research, 1, 119-128. (in Chinese) [毕列爵 (1983) 从19世纪到建国之前西方国家对我国进 行的植物资源调查. 武汉植物学研究, 1, 119-128.]

Chee YL (translated by Yin J) (2010) Different reaction on New Access and Benefit-Sharing Protocol. Bulletin of Biodiversity and Traditional Knowledge, 24(5), 1-4. (in Chinese) [殷金 (译) (2010) 对最新的获取与惠益分享议定书 的不同反应. 生物多样性与传统知识简报, 24(5), 1-4.]

Dong JZ, Yi ZL, Jiang JX (2005) Current situation of the research on the germplasm resources of medicinal plants in China. Journal of West China Forestry Science, 34(2), 95-101. (in Chinese with English abstract) [董静洲, 易自 力, 蒋建雄 (2005) 我国药用植物种质资源研究现状. 西 部林业科学, 34(2), 95-101.]

Flora Reipublicae Popularis Sinicae Editorial Committee (2004) Flora Reipublicae Popularis Sinicae. Science Press, Beijing. (in Chinese) [中国科学院《中国植物志》编辑委 员会 (2004) 中国植物志. 科学出版社, 北京.]

Greiber T, Moreno SP, Åhrén M, Carrasco GN, Kamau EC, Medaglia JC, Oliva MJ, Perron-Welch F, Ali A, Williams C(2012) An Explanatory Guide to the Nagoya Protocol on Access and Benefit-Sharing, International Union for Conservation of Nature and Natural Resources, pp.127. IUCN, Gland \& IUCN Environmental Law Centre, Bonn.

Huang JH, Chen JH, Ying JS, Ma KP (2011) Features and distribution patterns of Chinese endemic seed plant species. Journal of Systematics and Evolution, 49, 81-94.

Nijar GS (2011) Research Papers 36: The Nagoya Protocol on Access and Benefit Sharing of Genetic Resources: Analysis and Implantation Options for Developing Countries, pp. 1-43. South Centre, Geneva.

Qin HN (2013) China Checklist of Higher Plants, In the Biodiversity Committee of Chinese Academy of Sciences ed. Catalogue of Life China 2013 Annual Checklist. CD-ROM. Science Press, Beijing.

SCBD (Secretariat of Convention on Biological Diversity) (2011) X/1 Nagoya Protocol on Access to Genetic Resources and the Fair and Equitable Sharing of Benefits Arising from Their Utilization to the Convention on Biological 
Diversity: Text and Annex. In: Report of the Tenth Meeting of the Conference of the Parties to the Convention on Biological Diversity, Montreal, Canada. UNEP/CBD/COP/10/27, 76-92.

SCBD (Secretariat of Convention on Biological Diversity) (2016a) The Need for and Modalities of a Global Multilateral Benefit-Sharing Mechanism (Article 10). In: decision adopted by the parties to the Nagoya Protocol on access and benefit-sharing, Cancun, Mexico. UNEP/CBD/NP/MOP/ DEC/2/1.

SCBD (Secretariat of Convention on Biological Diversity) (2016b) Digital sequence information on genetic resources. In: decision adopted by the parties to the Nagoya Protocol on access and benefit-sharing, Cancun, Mexico. UNEP/ CBD/NP/MOP/DEC/2/14.

Wu JY, Xue DY, Zhao FW (2013) Plant genetic resources collection of some botanic gardens in the USA and UK from China. Resources Science, 35, 1499-1509. (in Chinese with English abstract) [武建勇, 薛达元, 赵富伟 (2013) 欧美 植物园引种中国植物遗传资源案例研究. 资源科学, 35, 1499-1509.]

Wu JY, Xue DY, Zhou KX (2011a) Past and present status of introduced plant genetic resources in China. Journal of Minzu University of China (Natural Sciences Edition), 20(2), 49-53. (in Chinese with English abstract) [武建勇, 薛达元, 周可新 (2011a) 中国植物遗传资源引进、引出或 流失历史与现状. 中央民族大学学报(自然科学版), 20(2), 49-53.]

Wu JY, Xue DY, Zhou KX (2011b) Diversity and dynamics of introduced plant from China in Royal Botanic Garden Edinburgh. Journal of Plant Genetic Resources, 12, 738-743. (in Chinese with English abstract) [武建勇, 薛达元, 周可 新 (2011b) 皇家爱丁堡植物园引种中国植物资源多样性 及动态. 植物遗传资源学报, 12, 738-743.]

Wu ZY (1991) The areal-types of Chinese genera of seed plants. Acta Botanica Yunnanica, Suppl. IV, 1-139. (in Chinese) [吴征镒 (1991) 中国种子植物属的分布区类型. 云南植物研究, 增刊IV, 1-139.]

Wu ZY, Raven PH, Hong DY (2013) Flora of China. Science Press, Beijing \& Missouri Botanical Garden Press, St. Louis.
Wu ZY, Zhou ZK, Li DZ, Peng H, Sun H (2003) The areal-types of the World families of seed plants. Acta Botanica Yunnanica, 25, 245-257. (in Chinese with English abstract) [吴征镒, 周浙昆, 李德铢, 彭华, 孙航 (2003) 世界种子 植物科的分布区类型系统. 云南植物研究, 25, 245-257.]

Xu J, Cai L, Wang AH, Xue DY, Yang QW, Li JS, Yin SL (2013) The global multilateral benefit-sharing mechanism: a new focus in genetic resources access and benefit-sharing negotiations. Biodiversity Science, 21, 127-131. (in Chinese with English abstract) [徐靖, 蔡蕾, 王爱华, 薛达元, 杨庆 文, 李俊生, 银森录 (2013) 全球多边惠益分享机制: 遗 传资源获取与惠益分享谈判的新焦点. 生物多样性, 21 , 127-131.]

Xue DY (2010) A new milestone of the Convention on Biological Diversity: Nagoya ABS Protocol (1st part). Environmental Protection, (23), 68-70. (in Chinese) [薛达元 (2010) 《生物多样性公约》新里程碑: 《名古屋ABS议定 书》(上). 环境保护, (23), 68-70.]

Xue DY, Qin TB, Cai L (2012) The Regime of Access and Benefit Sharing for Traditional Knowledge Associated with Genetic Resources. China Environmental Science Press, Beijing. (in Chinese with English summary) [薛达元, 秦天 宝, 蔡蕾 (2012) 遗传资源相关传统知识获取与惠益分 享制度研究. 中国环境科学出版社, 北京.]

Zhang HY, Zhao RH, Yuan CQ, Sun CQ, Zhang ZY (1995) China Journal of Chinese Materia Medica, 20, 387-390. (in Chinese) [张惠源, 赵润怀, 袁昌齐, 孙传奇, 张志英 (1995) 我国的中药资源种类. 中国中药杂志, 20, 387-390.]

Zhang XY (2017) A Study on the International Law of Genetic Resources. Intellectual Property Press, Beijing. (in Chinese) [张小勇 (2017) 遗传资源国际法问题研究. 知识产权出 版社, 北京.]

Zhao FW, Xue DY (2008) International trends and state legislation on access and benefit-sharing of genetic resources. Journal of Ecology and Rural Environment, 24, 92-96. (in Chinese with English abstract) [赵富伟, 薛达元 (2008) 遗 传资源获取与惠益分享制度的国际趋势及国家立法问题 探讨. 生态与农村环境学报, 24, 92-96.]

(责任编委: 杨庆文 责任编辑: 时意专) 